\title{
Piperine, a Pungent Alkaloid, Is Cytotoxic to Cultured Neurons from the Embryonic Rat Brain
}

\author{
Surachai UnChern, ${ }^{a, 1)}$ Koichi Nagata, ${ }^{a}$ Hiroshi Sarto, ${ }^{*, a}$ and Jun FukUdA ${ }^{b}$ \\ Department of Chemical Pharmacology, Faculty of Pharmaceutical Sciences, University of Tokyo, ${ }^{a}$ Tokyo 113, Japan \\ and Laboratory of Molecular and Cellular Physiology, National Defense Medical College, ${ }^{b}$ Saitama 359, Japan.
} Received July 9, 1993; accepted October 13, 1993

\begin{abstract}
The present study reveals that piperine, a pungent alkaloid present in various Piper species, is cytotoxic to cultured brain neurons. Exposure to piperine (12.5-100 $\mu \mathrm{M})$ for $72 \mathrm{~h}$ caused a concentration-dependent reduction in the survival of primary cultured neurons from various regions of the embryonic rat brain under high density cell culture conditions. There were relative regional differences in the susceptibility to cytotoxic effects of piperine in which septum and hippocampus showed higher vulnerability among the eight regions. The primary cultures of septal and hippocampal neurons under low density cell culture condition were performed to evaluate the contribution of non-neuronal cells. The concentration-response profiles in both high and low density cell culture conditions were comparable (septum: $\mathrm{EC}_{50}=43$ and $27 \mu \mathrm{M}$, hippocampus: $\mathrm{EC}_{50}=50$ and $44 \mu \mathrm{M}$, under high and low density cell culture conditions, respectively) suggesting a minor role of non-neuronal cells on cytotoxicity of piperine to developing neurons.
\end{abstract}

Keywords piperine; cytotoxicity; neuron; cell culture; neuronal survival

Pepper is one of the oldest and the most important member of the spices, and is still used extensively as a condiment and flavoring for all types of savory dishes. The pungency of pepper is due to the presence in the fruit of various resins and a yellow crystalline alkaloid, piperine (piperinoyl-piperidine), which is present to the extent of $4.5-8 \%{ }^{2)}$ Piperine is considered to be the active principle of various Piper species which are commonly used in folklore medicine for treatment of asthma, bronchitis, pyrexia, insomnia and abdominal disorders. ${ }^{3)} \mathrm{A}$ report on the acute toxicity of piperine was made with regard to mice, rats, and dogs with intraperitoneal and intragastic $\mathrm{LD}_{50}$ values ranging from 21.5 to $59.6 \mathrm{mg} / \mathrm{kg}$ body wt. ${ }^{4)}$ All animals, after receiving a fatal dose of piperine intraperitoneally, immediately exhibited an increase in locomotor activity. The activity progressively increased from running and jumping to convulsion, and finally death occurred with a whole body muscle spasm. The cause of death may be a certain type of neurotoxicity or respiratory paralysis. Various studies have shown that piperine possesses diverse biochemical and pharmacological activities include inhibition of drug metabolizing enzymes, ${ }^{5-8)}$ inhibition of liver mitochondrial bioenergetics $^{9)}$ and induction of substance $P$ and calcitonin generelated peptide (CGRP) release from sensory nerves, ${ }^{10}$ ) suggesting the substance's potential cytotoxicity. It is well documented that piperine causes central nervous system depression and exhibits antiepileptic activity. ${ }^{11-13)}$ The present study evaluated the cytotoxicity of piperine in developing neurons using primary cell cultures of embryonic rat brains.

Two different culture media were used in this study, modified Eagle's medium and chemically defined medium (DF/TIP). Modified Eagle's medium was composed of $7.42 \mathrm{mg} / \mathrm{ml}$ Eagle's MEM powder (Nissui Pharmaceutical) supplemented with $8.2 \mathrm{mg} / \mathrm{ml}$ glucose, $99 \mathrm{mg} / \mathrm{ml}$ sodium pyruvate, $0.29 \mathrm{mg} / \mathrm{ml} \mathrm{L-glutamine,} 1.7 \mathrm{mg} / \mathrm{ml}$ sodium bicarbonate, $87 \mathrm{units} / \mathrm{ml}$ penicillin $\mathrm{G}$ sodium (Sigma) and $90 \mu \mathrm{g} / \mathrm{ml}$ streptomycin sulfate (Sigma).
DF/TIP medium was composed of a $1: 1(\mathrm{v} / \mathrm{v})$ mixture of Dulbecco's modified Eagle's medium (Gibco) and Ham's nutrient mixture F-12 (Gibco) supplemented with $3.8 \mathrm{mg} / \mathrm{ml}$ sodium bicarbonate, $30 \mathrm{~nm}$ selenium, $15 \mathrm{~mm}$ HEPES buffer ( $\mathrm{pH} 7.4), 50$ units/ml penicillin $\mathrm{G}$ sodium (Sigma), $100 \mu \mathrm{g} / \mathrm{ml}$ streptomycin sulfate (Sigma), 100 $\mu \mathrm{g} / \mathrm{ml}$ human transferrin (Sigma), $10 \mu \mathrm{g} / \mathrm{ml}$ bovine insulin (Colaboratory Research) and $20 \mathrm{~nm}$ progesterone (Sigma). Piperine (Aldrich) was dissolved in dimethyl sulfoxide (DMSO). The final concentrations of DMSO in cell cultures were $0.2 \%$. In our preliminary experiments, there was no significant difference in neuronal survival or neurite extension with or without $0.2 \%$ of DMSO in culture medium.

Dissociated cell cultures were prepared from dissected brain regions of embryonic day 18 Wistar rats (cerebral cortex, hippocampus, septum, striatum, thalamus, ventral midbrain, colliculus and cerebellum). Dissected tissues were cut into pieces and incubated for $20 \mathrm{~min}$ at $37^{\circ} \mathrm{C}$ with $0.25 \%$ trypsin (Difco, $1: 250$ ) and $0.01 \%$ DNase I (Sigma) in $\mathrm{Ca}^{2+}, \mathrm{Mg}^{2+}$-free Hank's balanced salt solution. The incubation was terminated by the addition of heat-inactivated horse serum (Cell Culture Laboratories) and tissue fragments were centrifuged at $1200 \mathrm{rpm}$ for $5 \mathrm{~min}$. The tissue pellet was gently rinsed and resuspended in modified Eagle's medium containing $10 \%$ fetal bovine serum (FBS; Gibco). The single cells were dissociated by gently passing the suspension through a flame-polished Pasteur pipette 10 to 15 times. The cell suspension was filtered through two sheets of nylon net $(50 \mu \mathrm{m}$-mesh) to remove cell lumps, and was further diluted with modified Eagle's medium containing 10\% FBS and plated on poly-L-lysine-coated plates to make either high density or low density cell cultures. The two procedures were different in certain steps so as to provide a suitable condition for each type of culture.

Under high density culture condition, cells were plated at a density of 100000 cells $/ \mathrm{cm}^{2}$ in 48 -well plates (Costar, $1 \mathrm{~cm}^{2} /$ well). They were cultured at $37^{\circ} \mathrm{C}$ for $24 \mathrm{~h}$ in a 

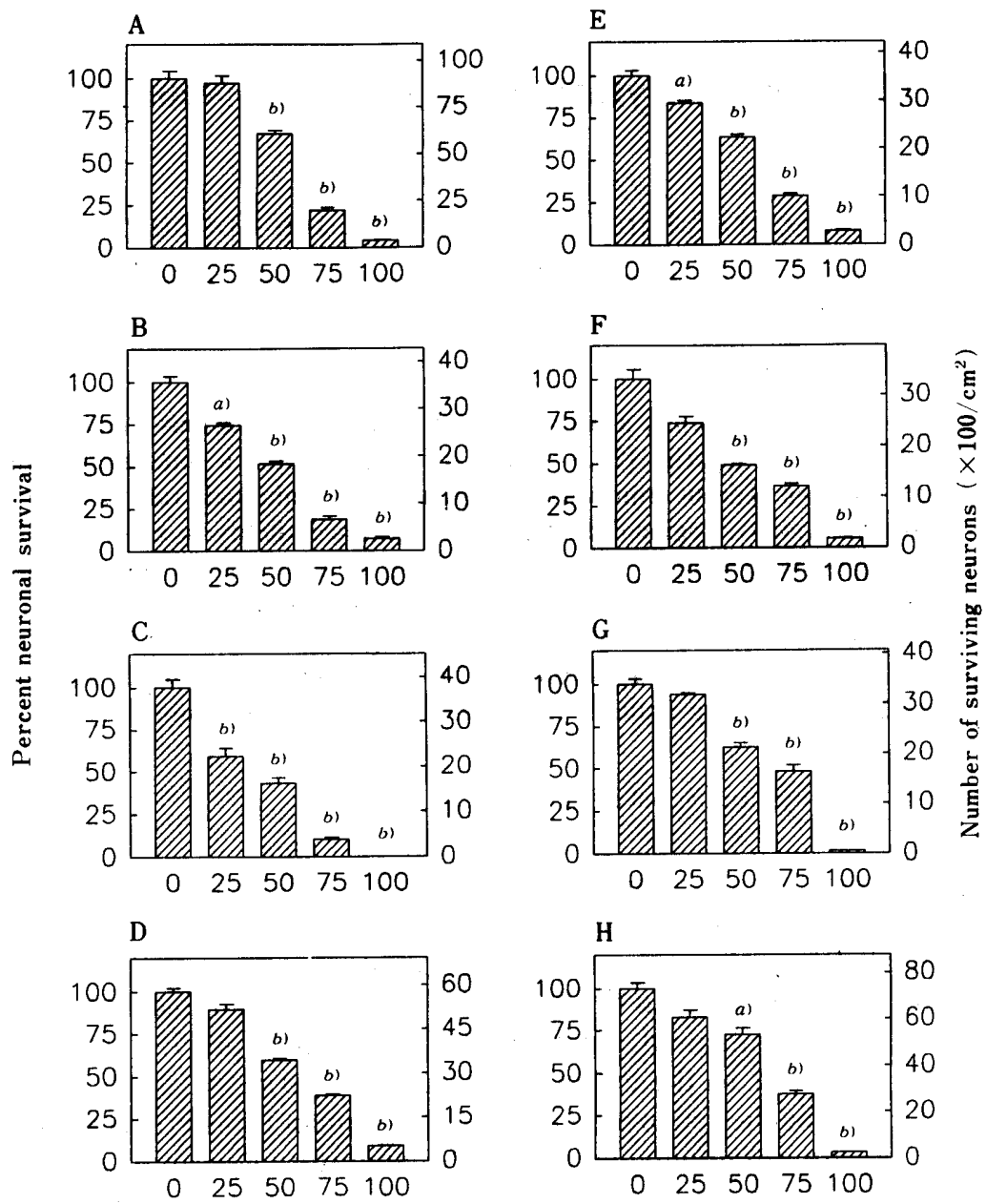

Piperine concentration $(\mu \mathrm{M})$

Fig. 1. Concentration-dependent Inhibitory Effects of Piperine on Neuronal Survival in High Density Cell Cultures from Various Brain Regions Data are expressed as mean \pm S.E.M. $(n=4)$. Differences $a) p<0.05, b) p<0.01$ by one way ANOVA and Tukey HSD multiple comparison compared to control culture. The values of $\mathrm{EC}_{30}$ in $\mu \mathrm{M}$ estimated by regression analysis of concentration-response curves: septum, 43; hippocampus, 50; thalamus, 54; ventral midbrain, 57; cerebral cortex, 58; striatum and cerebellum, 60; coliculus, 62 . A, cerebral cortex; B, hippocampus; C, septum; D, striatum; E, ventral midbrain; F, thalamus; G, colliculus; H, cerebellum.

humidified $5 \% \mathrm{CO}_{2}-95 \%$ air atmosphere and the medium was changed to DF/TIP medium with or without the desired concentrations of piperine. In the case of low density culture, cells were plated at a density of 2500 or 5000 cells $/ \mathrm{cm}^{2}$ in 24-well plates (Falcon, $2 \mathrm{~cm}^{2} /$ well). They were cultured in serum-containing medium for only $3 \mathrm{~h}$ and the medium was changed to modified Eagle's medium containing $100 \mu \mathrm{g} / \mathrm{ml}$ human transferin, $10 \mu \mathrm{g} / \mathrm{ml}$ bovine insulin and $20 \mathrm{nM}$ progesterone with or without the desired concentrations of piperine.

After $72 \mathrm{~h}$ of incubation, both types of cultures were fixed with $4 \%$ paraformaldehyde for $30 \mathrm{~min}$ at $4{ }^{\circ} \mathrm{C}$. High density cultures were immunostained with mouse monoclonal antibody to MAP2 proteins (Boehringer Mannheim Biochemical) and visualized with the peroxidase-antiperoxidase method (Vectastain ABC Kit). Low density cultures were stained with Coomassie brilliant blue (Bio-Rad Laboratories). The stained cultures were analyzed for neuronal survival by counting MAP2immunoreactive or blue-stained neuron-like cells which had one neurite more than 2 times the soma diameter under an inverted microscope. In each case, neurons in 6 to $8 \%$ of the whole area were randomly counted. Data were presented as the number of surviving neurons $/ \mathrm{cm}^{2}$ and as percent neuronal survival of which control cultures were normalized to $100 \%$.

After exposure to piperine for $72 \mathrm{~h}$, the number of surviving neurons in high density cultures from various brain regions had decreased in a concentration-dependent manner (Figs. 1, 3A and 3C). Many neurons surviving in high piperine concentrations displayed in irregular shape based on MAP2-immunoreactivity. These changes in cellular morphology may be due to the effect of piperine on the organization and distribution of the microtubular structure. In addition, neurite outgrowth in the presence of piperine was remarkably suppressed. Among eight brain regions tested, septum and hippocampus were relatively more sensitive to lower concentrations of piperine. The values of median effective concentration $\left(\mathrm{EC}_{50}\right)$ in $\mu \mathrm{M}$ estimated by regression analysis of concentration-response curves are as follows: septum, 43; hippocampus, 50; thalamus, 54; ventral midbrain, 57; cerebral cortex, 58; striatum and cerebellum, 60; colliculus, 62 . Septum which appeared to be the most susceptible brain region, and neurons always completely died at $100 \mu \mathrm{M}$ of piperine. Therefore, these findings suggest that piperine is cytotoxic to cultured brain neurons. The effects observed may be indirectly mediated through the diminution of non- 


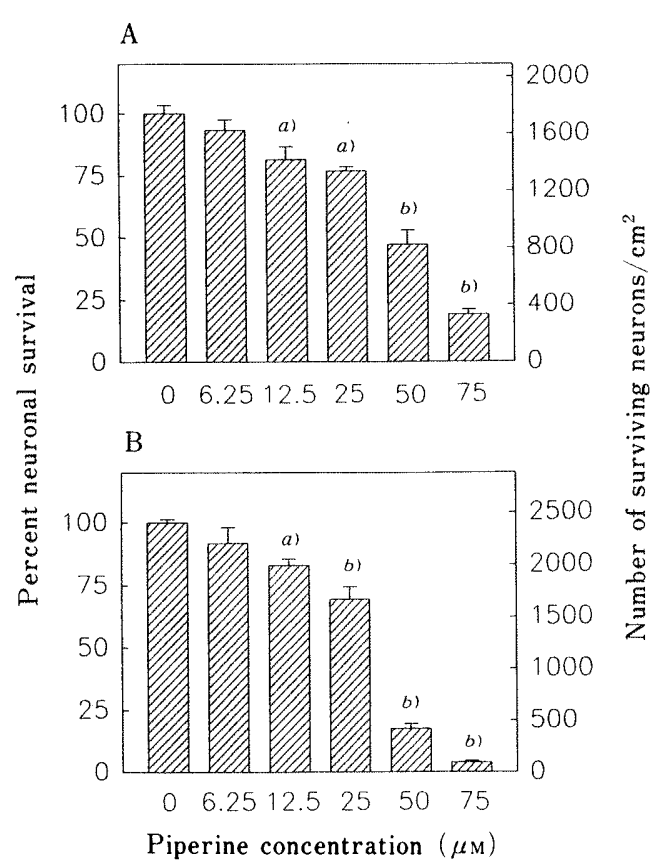

Fig. 2. Concentration-dependent Inhibitory Effects of Piperine on Neuronal Survival in Low Density Cell Cultures from Hippocampus (A) and Septum (B)

Data were expressed as mean \pm S.E.M. $(n=8)$. Differences $a) p<0.05, b) p<0.01$ by one way ANOVA and Tukey HSD multiple comparison compared to control culture. The values of $\mathrm{EC}_{50}$ in $\mu \mathrm{M}$ estimated by regression analysis of concentration-response curves: septum, 27; hippocampus, 44.

high density culture
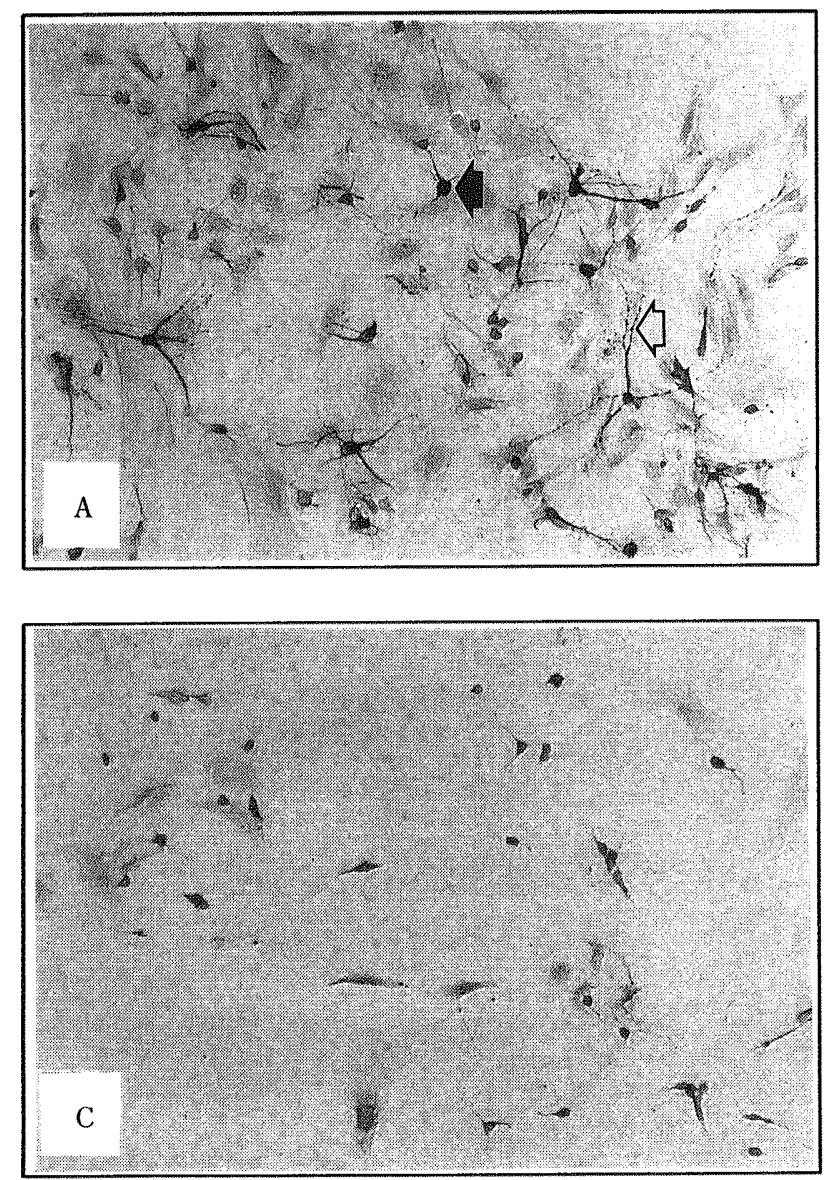

neuronal cell support under high density cultue condition. To verify this possibility, we further studied the effects of piperine on the survival of neurons in low density cell cultures in which the influence from non-neuronal cells was minimized. Only septum and hippocampus which showed higher vulnerability were included in these experiments and a lower range of piperine concentrations was applied. The non-neuronal population, based on morphological criteria, in low density cultures of these two brain regions was found to be less than $5 \%$. In low density cell cultures, piperine clearly exerted cytotoxic effects on septal and hippocampal neurons similar to those in high density cell cultures (Figs. 2, 3B and 3D). The concentration-response relationships under the two conditions were comparable (septum: $\mathrm{EC}_{50}=43$ and $27 \mu \mathrm{M}$, hippocampus: $\mathrm{EC}_{50}=50$ and $44 \mu \mathrm{M}$, under high and low density cell culture conditions, respectively), suggesting a similar mode of action and a minor contribution of non-neuronal cells in the cytotoxic effects of piperine. This also indicated that decreased neuronal survival under high density culture condition was mainly due to the direct effects of piperine on neurons. In spite of the exposure to piperine, nonneuronal cells in high density culture may survive and their neuron-supporting role may still be operative. This partially counteracted the harmful effects of piperine as suggested by relatively higher $\mathrm{EC}_{50}$ values under high
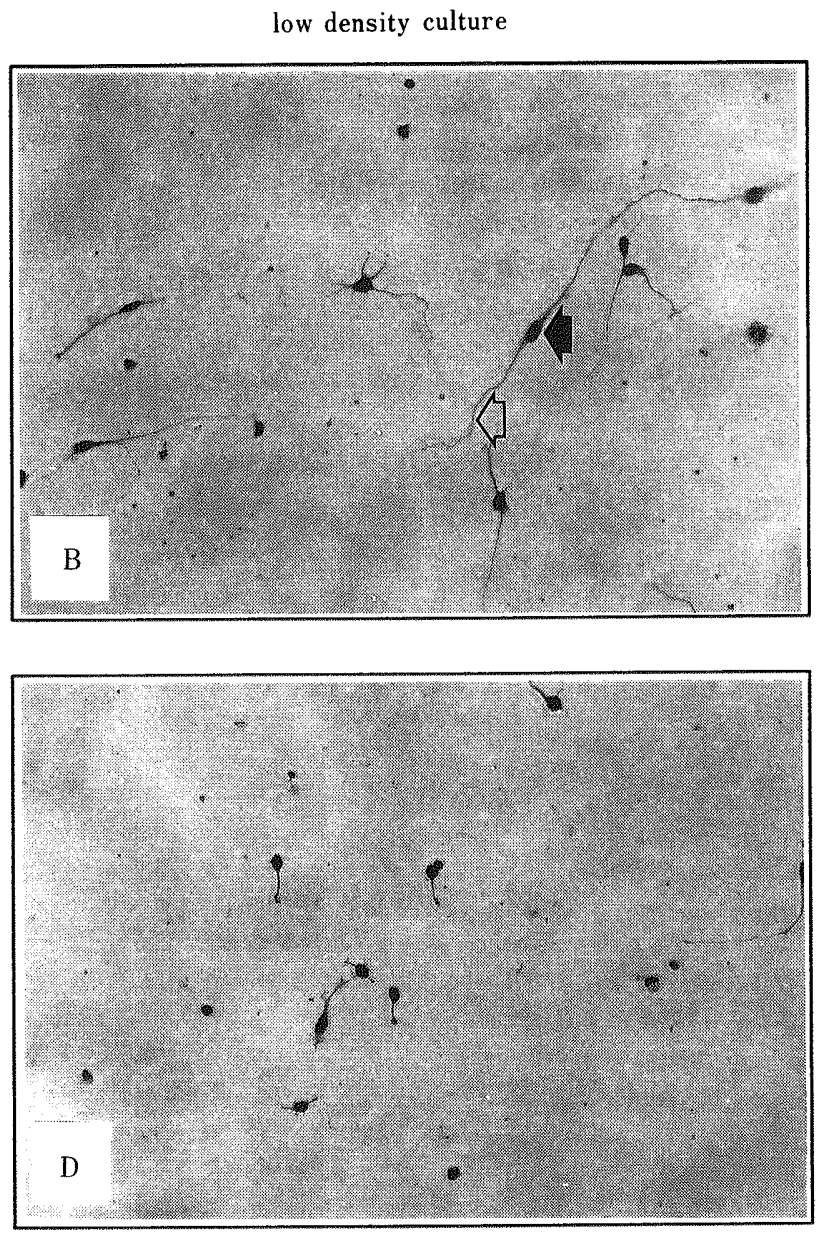

Fig. 3. Comparative Cytotoxic Effects of Piperine on Cultured Septal Neurons under High and Low Density Cell Culture Conditions

A: and B: control cultures. C: and D: cultures exposed to $50 \mu \mathrm{m}$ piperine. Cells in high density cultures were stained with anti-MAP2 antibody and those in low density cultures were stained with Coomassie Brilliant blue. Filled arrows indicate cell body and empty arrows indicate neurites. Bar: $100 \mu \mathrm{m}$. 
density cell culture condition. This notion was supported by separate preliminary experiments with astrocyte cell culture. It was demonstrated that $72 \mathrm{~h}$ exposure to piperine in a concentration range of 25 to $100 \mu \mathrm{M}$ markedly inhibited $\left[{ }^{3} \mathrm{H}\right]$ thymidine incorporation into astrocyte cell cultures without any change in protein contents (data not shown). There were no significant changes in astrocyte morphology. These results suggest that astrocyte proliferation but not survival was affected by piperine.

Taken together, this study reveals that piperine decreases the survival of developing brain neurons in culture. This cytotoxic effect is mainly mediated by direct action of piperine on neurons, although the indirect effect contributed by non-neuronal influence cannot be totally disregarded. Astrocytes appear to be susceptible to piperine toxicity as well but they are likely to be more tolerant than neurons. The mechanism underlying piperine actions on neurons and astrocytes warrants further study.

Acknowledgement We thank Chulalongkorn University for short-term fellowship support of Surachai Unchern.

\section{REFERENCES}

1) Present address: Department of Pharmacology, Faculty of Pharmaceutical Sciences, Chulalongkorn University, Bangkok 10330, Thailand.

2) V. S. Govindarajan, Crit. Rev. Food Sci. Nutr., 9115 (1977).

3) C. K. Atal; K. L. Dhar, J. Singh, Lloydia, 38, 256 (1975).

4) P. Piyachaturawat, T. Glinsukon, C. Toskulkao, Toxicol. Lett., 16 351 (1983).

5) C. K. Atal, R. K. Dubey, J. Singh, J. Pharmacol. Exp. Ther., 232, 258 (1985).

6) G. Bano, V. Amal, R. K. Raina, U. Zutshi, C. L. Chopra, Planta Medica, 53, 568 (1987).

7) G. Bano, R. K. Raina, U. Zutshi, K. L. Bedi, R. K. Johri, S. C. Sharma, Eur. J. Clin. Pharmacol., 41, 615 (1991).

8) R. R. Dalvi, P. S. Dalvi, Drug Metabol. Drug Interact, 9, 23 (1991).

9) W. Reanmongkol, W. Janthasoot, W. Wattanatorn, P. DhummaUpakorn, P. Chudapongse, Biochem. Pharmacol., 37, 753 (1988).

10) M. Takaki, J. G. Jin, Y. F. Lu, S. Nakayama, Eur. J. Pharmacol., 186, 71 (1990).

11) E. B. Lee, K. H. Shin, W. S. Woo, Arch. Pharmacol. Res., 7, 127 (1984).

12) Y. Q. Pei, Epilepsia, 24, 177 (1983).

13) W. S. Woo, E. B. Lee, K. H. Shin, Arch. Pharmacol. Res., 2, 121 (1979). 